\title{
Ceramic membrane filtration of produced water: impact of membrane module
}

Zsirai, T. ${ }^{1,2}$, Al-Jaml A. K. ${ }^{2}$, Qiblawey, H. ${ }^{2}$, Al-Marri, M. ${ }^{1}$, Ahmed, A. ${ }^{3}$, Bach, S. ${ }^{3}$, Watson, S. ${ }^{4}$, Judd S.*1

${ }^{1}$ Gas Processing Centre, Qatar University, Doha, Qatar

${ }^{2}$ Department of Chemical Engineering, Qatar University, Doha, Qatar

${ }^{3}$ Maersk Oil Research and Technical Centre, Doha, Qatar

${ }^{4}$ Maersk Oil Qatar, Doha, Qatar

*corresponding author, simon.judd@qu.edu.qa

\section{Abstract}

Produced water (PW) generated from oil exploration requires rigorous removal of suspended matter (free oil and particulate solids) as tertiary treatment (downstream of hydrocyclone and gas flotation) if it is to be re-injected into low-permeability reservoirs. The viability of membrane filtration for this duty is largely dependent on sustaining a high membrane flux to minimise the process footprint.

A pilot-scale study of PW filtration using crossflow multi-channel ceramic membrane technology has been conducted to identify the appropriate membrane characteristics for sustaining the flux whilst maintaining the required treated water quality. Membranes based on two materials (silicon carbide, $\mathrm{SiC}$, and titanium dioxide, $\mathrm{TiO}_{2}$ ) and two different pore sizes were challenged with real PW samples taken from oil platforms operating on the Arabian Gulf. The membranes were characterised according to the overall permeability decline rate and the end permeability.

Results suggest that $\mathrm{SiC}$ membranes outperform $\mathrm{TiO}_{2}$ ones with respect to sustainable permeability under the same operating and maintenance conditions. The SiC microfiltration membrane provided anomalously high permeabilities but also the highest fouling propensity. Results suggest that whilst the high fluxes (1300-1800 $\mathrm{L} \mathrm{m}^{-2} \mathrm{~h}^{-1}$ ) are attainable for the technology, this is contingent upon the application of an effective chemical clean.

Keywords Produced water; ceramic membranes; titanium dioxide; silicon carbide; permeability; fouling; turbidity; $O \& G$.

\section{$1 \quad$ Introduction}

Produced water (PW) from oil and gas exploration represents the most significant volume waste product of the petroleum industry, and demands treatment for oil and solids removal prior to discharge. For offshore platforms, produced water reinjection (PWRI) back into the aquifer offers a sustainable disposal route due to the significantly reduced net environmental impact: the PW is employed in place of the seawater to displace the oil, and is reused (Bader, 2007; Robinson 2013). All additives are also subsequently largely reused, provided they remain in the aqueous phase. However, for "tight" or low permeability reservoirs - associated with carbonate strata - PWRI demands removal of particles down to $3-5 \mu \mathrm{m}$ in size and $<5 \mathrm{mg} / \mathrm{L}$ concentration 
(Li and Lee et al., 2009; Robinson, 2013; Judd et al, 2014) so as to limit plugging of the reservoir pores and sustain oil displacement. Moreover, the technologies must be robust to fluctuating loads of suspended and sparingly soluble materials, where the latter can form scales both within the reservoir and the unit process itself (Robinson, 2010). Finally, the removal of microbial species, and specifically sulphate-reducing bacteria, would be expected to mitigate against the build-up of highly insoluble sulphide salts in the reservoir.

Significant research into membrane filtration technologies (ultrafiltration, UF, and microfiltration, MF) for PW tertiary treatment has been reported over the past 20 years, with increasing focus on ceramic membranes (CMs) operated in the crossflow mode. Operation in the crossflow, rather than dead-end, mode permits longer filtration cycles since the shear acting on the membrane as the retentate flows across it serves to suppress membrane fouling. CMs offer the advantage over polymeric materials of increased fouling resistance and operation at elevated temperatures. Their application to PW dates back to trials conducted in the early 1990s (Zaidi et al, 1992), with a significant number of studies performed since that time (Table 1).

Recent reviews (Alzahrani and Mohammad, 2014; Padaki et al, 2015) have tended to demonstrate a propensity for bench-scale studies based on analogue wastewaters, with studies based on real petroleum wastewaters tending to relate to refineries (Zhong et al, 2003; Madaeni et al, 2013; Weschenfelder et al, 2015ab). Demonstration-scale studies, conducted under conditions fully representative of those prevailing at full scale (Lee et al 2005; Pedenaud et al, 2011; Prado-Rubia et al, 2012), are limited in experimental detail and are not necessarily subject to rigorous control of the filtration operating conditions. Against this, trials conducted on both PW and analogues of the effluent have tended to demonstrate the significantly more challenging nature of PW than analogue waters (Ebrahimi et al, 2010; Chakrabarty et al, 2010; Weschenfelder et al, 2015a). Evidence suggests that both the dissolved (Hua et al, 2007; Abassi et al, 2012) and suspended (Wang et al, 2012) content of PW impacts on flux.

The filtration profile of crossflow MF/UF CMs challenged with PW and operated under constant conditions of transmembrane pressure (TMP) is typified by a rapid decline in flux to a neosteady-state value. The decline appears to be dependent on a number of different system parameters, including feedwater composition, hydraulics (primarily crossflow velocity, CFV), and temperature, as well as the characteristics of the membrane itself. The rapid flux decline demands both physical cleaning, i.e. backflushing or backpulsing, and chemical cleaning in place (CIP) to sustain the flux, with physical cleaning efficacy demonstrated in a number of studies ( $\mathrm{Li}$ and Lee, 2009; Ebrahimi et al, 2010, 2012; Silalahi and Leiknes, 2011; Reyhani et al, 2015; Weschenfelder et al, 2015ab). As a consequence of the large number of variables impacting on operation, reported permeability values for CMs challenged with PW or its analogues have been very wide-ranging, from below 20 to $\sim 800 \mathrm{LMH} /$ bar (Table 1 ). 
Table 1: Studies of MF/UF membrane filtration of PW

\begin{tabular}{|c|c|c|c|c|c|c|c|c|c|c|c|}
\hline $\begin{array}{l}\text { Oil concn } m g / L, \\
\text { water source }\end{array}$ & Scale & Material & $\begin{array}{l}\text { Pore } \\
\text { size } \\
\mu m\end{array}$ & $\begin{array}{l}\text { Init flux, } \\
\text { LMH }\end{array}$ & $\begin{array}{l}\text { Fin flux, } \\
\text { LMH }\end{array}$ & $T M P, b a r$ & $\begin{array}{c}\text { Fin perm } \\
\text { (range), } \\
\text { LMH/bar }\end{array}$ & $\begin{array}{l}\text { time, } \\
\quad h\end{array}$ & $C F V, \mathrm{~m} / \mathrm{s}$ & $T,{ }^{\circ} \mathrm{C}$ & $\operatorname{Ref}$ \\
\hline \multirow[t]{2}{*}{ 250, synth PW } & $\mathrm{b}(\mathrm{m})$ & $\mathrm{AlO}$ & 0.2 & 200 & 26 & 0.7 & 18 & 2 & $0.24-0.91$ & 40 & Mueller et al, 1997 \\
\hline & $\mathrm{b}(\mathrm{m})$ & $\mathrm{AlO}$ & 0.8 & 1000 & 44 & 0.7 & 32 & 2 & $0.24-0.91$ & 40 & \\
\hline \multirow[t]{2}{*}{ 5000, synth PW } & b & $\mathrm{AlO}$ & 0.2 & 110 & 22 & 1.25 ave & 18 & 2 & $3-5$ & - & Yang et al, 1998 \\
\hline & b & $\mathrm{ZrO}$ & 0.2 & 130 & 93 & & 74 & 2 & $3-5$ & - & \\
\hline 6000 , refinery & $\mathrm{b}$ & $\mathrm{ZrO}$ & 0.2 & 240 & 120 & 1.1 & 109 & 1 & 2.6 & $25-60$ & Zhong et al, 2003 \\
\hline 6000 , refinery & $\mathrm{b}$ & $\mathrm{ZrO}$ & 0.2 & 240 & 175 & 1.1 & 159 & 1 & 2.6 & $25-60$ & \\
\hline 200-2000, veget. oil & $\mathrm{b}(\mathrm{m})$ & $\mathrm{AlO}$ & 0.05 & - & $125-165$ & $0.5-3$ & $50-200$ & - & $0.2-1.7$ & $20-21$ & Hua et al, 2007 \\
\hline 50000 , synth cutting & $\mathrm{b}(\mathrm{m})$ & $\mathrm{ZrO}$ & 0.02 & - & $100-200$ & $0.8-4.5$ & 44-125 & - & 3 & 50 & Vitai et al, 2009 \\
\hline \multirow[t]{3}{*}{ oil } & $\mathrm{b}(\mathrm{m})$ & PAEK & $100^{2}$ & - & $140-170$ & $1-4.5$ & $38-140$ & - & 3 & 50 & \\
\hline & $\mathrm{b}(\mathrm{m})$ & $\mathrm{ZrO}$ & 0.02 & - & 35 & $0.8-4.5$ & 8-88 & - & $0.6-3$ & 50 & \\
\hline & $\mathrm{b}(\mathrm{m})$ & PAEK & 100 & - & 25 & $0.1-4.5$ & $6-44$ & - & $0.6-3$ & 50 & \\
\hline \multirow[t]{2}{*}{ 366, PW } & $\mathrm{b}$ & $\mathrm{PS}^{1}$ & 0.007 & 225 & 128 & $1-1.7$ & & 1 & - & - & Chakrabarty et al, 2010 \\
\hline & $\mathrm{b}$ & $\mathrm{PS}^{1}$ & 0.006 & 100 & 70 & $1-1.7$ & & 1 & - & - & \\
\hline 200-1000, tank & $\mathrm{b}(\mathrm{m})$ & $\mathrm{AlO}$ & 0.2 & 128 & 28 & 1 & 28 & 2 & - & 60 & Ebrahimi et al, 2010 \\
\hline \multirow[t]{2}{*}{ dewatering effl. } & $\mathrm{b}(\mathrm{m})$ & $\mathrm{TiO}$ & 0.05 & 80 & 4 & 1 & $<5$ & 2.5 & - & 60 & \\
\hline & $\mathrm{b}(\mathrm{m})$ & & & 120 & 30 & 1 & $120-30$ & 2 & - & 60 & \\
\hline 50-350, synth & $\mathrm{p}$ & $\mathrm{AlO}$ & $0.1-0.5$ & - & 80-175 & $0.06-0.25$ & $400-800$ & 2 & 4.5 & 27 & Silalahi \& Leiknes, 2011 \\
\hline -, gas field PW & $\mathrm{p}$ & $\mathrm{Al}-\mathrm{ZrO}$ & 0.05 & - & 170-255 & - & $190-250$ & 600 & - & 25 & Subramani et al, 2011 \\
\hline 1000, synth C8-C12 & $\mathrm{b}$ & Mullite $^{1}$ & 0.29 & 100 & $70-75$ & 3 & 33-23 & 2 & $1.5-2$ & 25 & Abassi et al, 2012 \\
\hline 3000 , refinery & $\mathrm{b}$ & PS & $0.1-0.2$ & 145 & 65 & 1.5 & $50-15$ & 11 & 1.25 & 27 & Madaeni et al, 2013 \\
\hline \multirow[t]{2}{*}{-, SAGD effl. } & $\mathrm{p}$ & $\mathrm{AlO}$ & 0.05 & 200 & - & 1.52 & 132 & - & - & 45 & Guirgis et al, 2015 \\
\hline & $\mathrm{p}$ & $\mathrm{ZrO}$ & $20^{2}$ & 200 & - & 1.52 & 45 & - & - & 45 & \\
\hline 100 , synth & $b, p$ & $\mathrm{ZrO}$ & 0.1 & 910 & 194-240 & 2 & 97-120 & 24 & 2 & 25 & Weschenfelder et al, \\
\hline$\sim 60$, refinery effl. & $b, p$ & $\mathrm{ZrO}$ & 0.1 & 910 & 175 & 2 & 88 & 24 & 2 & 25 & $2015 a$ \\
\hline$\sim 250$, refinery effl. & $\mathrm{b}$ & $\mathrm{ZrO}$ & 0.1 & 1000 & 290 & 1.5 & 193 & - & 3 & 45 & $\begin{array}{l}\text { Weschenfelder et al, } \\
2015 b\end{array}$ \\
\hline \multirow[t]{2}{*}{ 9/43, PW } & $\mathrm{p}$ & $\mathrm{AlO}$ & 0.2 & - & 295-312 & 2.5 & 118-125 & - & 3 & $35-60$ & Reyhania \& Meighani, \\
\hline & $\mathrm{b}$ & PAN & $20^{2}$ & - & 104-280 & 5 & $20-36$ & - & 1.5 & $25-55$ & 2015 \\
\hline
\end{tabular}

KEY LMH litres per $\mathrm{m}^{2}$ per hr; TMP transmembrane pressure; CFV crossflow velocity $\mathrm{b}$ bench; $\mathrm{b}(\mathrm{m})$ bench, based on membrane module; $\mathrm{p}$ pilot; AlO aluminium oxide; PAEK polyaryletherketone; PAN polyacrylonitrile PS polysulphone; TiO titanium oxide; $\mathrm{ZrO}$ zirconium oxide

${ }^{1}$ bespoke membranes; ${ }^{2}$ molecular weight cut-off 
Whilst the studies of CMs challenged with oil-laden waters have been extensive, they have tended to be constrained either by feedstock availability, limiting the filtration time (to 1-2 hours for many of the studies listed in Table 1), and/or by recourse to analogues. On the other hand, evidence from demonstration trials (Lee et al, 2005; Pedenaud et al 2011) and recent extended trials (Weschenfelder et al, 2015b) indicate very significant permeability loss over a period of several days. There have also been few studies comparing candidate CM materials; comparative studies have tended to focus on the relative performance of ceramic and polymeric membranes (Vitai et al, 2009; Reyhani and Meighani, 2015). Studies which include CM chemical cleaning efficacy (Ebrahimi et al, 2010; Weschenfelder et al, 2015b) have not encompassed long-term use of the cleaned membrane. Moreover, the CMs investigated have been largely limited to oxides of aluminium, zirconium and titanium, with few controlled studies of silicon carbide ( $\mathrm{SiC})$.

This study aims to address the above using real PW samples taken from oil platforms operating on the Arabian Gulf and a multi-stream pilot plant fitted single and multi-channel membranes. Two different CM materials of two different pore sizes have been used. An operating protocol was developed which allowed the installed membranes to be challenged with a range of feedwater suspended oil concentrations over an extended time period. The programme aimed to permit a comprehensive and quantitative appraisal of the relative efficacy of the different membranes for sustaining both treated water quality and membrane permeability.

\section{Materials and Methods}

\section{$2.1 \quad$ Materials}

The pilot plant (Fig. 1) comprised two streams of tubular membrane modules, of varying characteristics (Table 2), operated in crossflow mode. The plant, supplied by Liqtech International (Ballerup, Denmark), allowed operation at a fixed conversion with automated physical cleaning provided by backflushing and backpulsing and manually-applied chemical cleaning in place (CIP). Recirculation of both retentate and permeate streams was possible, with retentate recirculation used to increase the feedwater suspended oil concentration.

All silicon carbide ( $\mathrm{SiC})$ membranes were provided by Liqtech, and titanium dioxide $\left(\mathrm{TiO}_{2}\right)$ ones by TAMI Industries (Nyons, France). Four membranes were studied, the elements all being $~ 305 \mathrm{~mm}$ in length and $25 \mathrm{~mm}$ diameter and with various specifications of material type, channel characteristics (number, dimensions and geometry) and pore size (Table 2).

Table 2: Membrane modules, $305 \mathrm{~mm}$ length, $25 \mathrm{~mm}$ diameter.

\begin{tabular}{c|ccccccccc}
\hline $\begin{array}{l}\text { Membrane } \\
\text { material }\end{array}$ & $\begin{array}{c}\text { No. of } \\
\text { channels }\end{array}$ & $\begin{array}{c}\text { Channel } \\
\text { diameter } \\
m m\end{array}$ & $\begin{array}{c}\text { Channel } \\
\text { geometry }\end{array}$ & $\begin{array}{c}\text { Area } \\
m^{2}\end{array}$ & $\begin{array}{c}\text { Pore } \\
\text { size } \\
\mu m\end{array}$ & $\begin{array}{c}\text { Flow } \\
\text { rate } \\
m^{3} / h r\end{array}$ & $\begin{array}{c}\text { Init. Flux } \\
\text { LMH }\end{array}$ & $\begin{array}{c}\text { Init. perm. } \\
\text { LMH/bar }\end{array}$ & $\begin{array}{c}\text { Time to } \\
\text { conc. } \\
\text { hrs }\end{array}$ \\
\hline $\mathrm{SiC} \mathrm{MF}$ & 37 & 3 & Circular & 0.09 & 0.5 & 1.6 & $2000-2700$ & $7200-8400$ & $1-15$ \\
$\mathrm{SiC} \mathrm{UF}$ & 37 & 3 & Circular & 0.09 & 0.04 & 1.6 & $630-780$ & $1500-1900$ & $8-9$ \\
$\mathrm{TiO}_{2} \mathrm{MF}$ & 39 & 2.5 & Triangular & 0.131 & 2 & 1.5 & $150-200$ & $350-600$ & $16.5-17.5$ \\
$\mathrm{TiO}_{2} \mathrm{UF}$ & 39 & 2.5 & Triangular & 0.131 & $50^{2}$ & 1.5 & $50-100$ & $200-250$ & $28-29$ \\
\hline
\end{tabular}

${ }^{1}$ Approach volumetric flow rate. ${ }^{2}$ Molecular weight cut-off, $k D a$

The PW was sampled downstream of the induced gas flotation (IGF) stage of a classical hydrocyclone-IGF PW treatment train. It was shipped in three lots of 5-tonne batches from an oil platform operating in the Arabian Gulf. PW was transferred to a storage tank and 
nitrogen-blanketed for the period of the trials to suppress oxidation. Water samples taken from the feed tank before and after the test period were analysed for turbidity and oil and grease $(\mathrm{O} \& \mathrm{G})$ was according to standard methods SMWW $2130 \mathrm{~B}$ and $5520 \mathrm{C}$ respectively (APHA, 2001. Concentration values for major constituents, i.e. those reduced in concentration by permeation, are given in Table 3 .

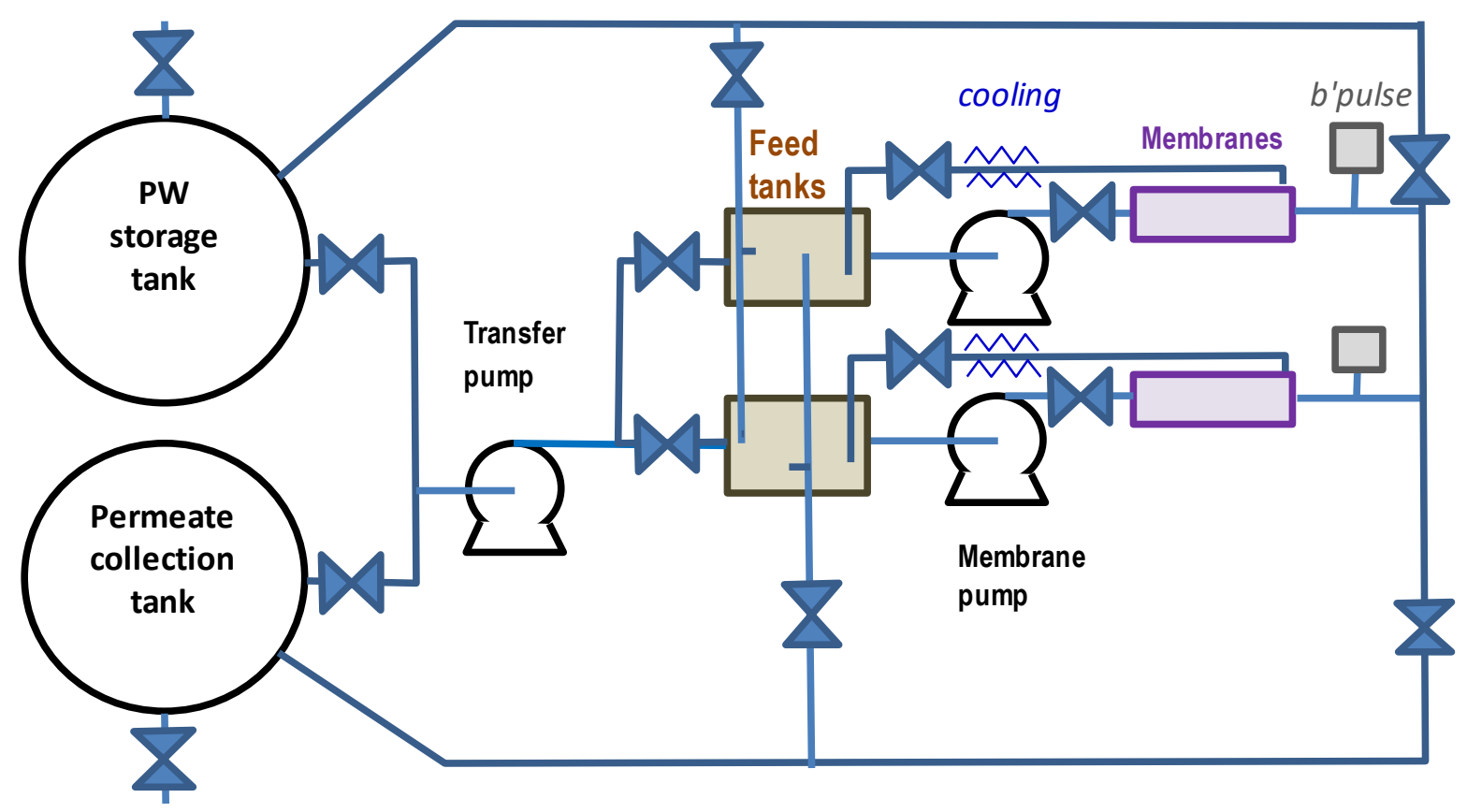

Figure 1: Pilot plant

Table 3: Feedwater and permeate characteristics for inert dissolved constituents, Batches $A$ - $C$

\begin{tabular}{|c|c|c|c|c|c|c|c|c|c|}
\hline \multirow{2}{*}{ Parameter, dimension, $\quad(S M W W$} & \multicolumn{3}{|c|}{$A$} & \multicolumn{3}{|c|}{$B$} & \multicolumn{3}{|c|}{$C$} \\
\hline & $\mathrm{AVG}$ & S.D. & S.D. (\%) & $\mathrm{AVG}$ & S.D. & S.D. $(\%)$ & $\mathrm{AVG}$ & S.D. & S.D. (\%) \\
\hline $\mathrm{pH}\left(4500 H^{+} . B\right)$ & 7.3 & 0.5 & 6.5 & 6.7 & 0.9 & 13.2 & 7.5 & 0.4 & 4.7 \\
\hline Conductivity, $\mathrm{mS} / \mathrm{cm},(2510 \mathrm{~B})$ & 94.3 & 2.4 & 2.6 & 95.7 & 2.4 & 2.6 & 101 & 1.3 & 1.3 \\
\hline Sulphide, ppm as $\mathrm{S},(4500-S 2 D)$ & 0.1 & 0.1 & 116 & 0.1 & 0.2 & 121 & 0.1 & 0.1 & 114 \\
\hline Total Solids (TS), g/L, $(2540 \mathrm{~B})$ & 79 & 6.1 & 7.7 & 82 & 4.1 & 5 & 86 & 5.6 & 6.5 \\
\hline Total Organic Carbon, mg/l, (5310) & 237 & 91 & 38 & 80 & 47 & 60 & 46 & 72 & 156 \\
\hline Hardness, g/L, $(2340 \mathrm{C})$ & 13.4 & 0.39 & 3.0 & 14.5 & 0.55 & 3.8 & 9.7 & 3.23 & 33.4 \\
\hline Iron, $\mathrm{mg} / \mathrm{L},(2340 \mathrm{C})$ & 2.5 & 1.8 & 72.4 & 0.9 & 0.6 & 72.7 & 3.1 & 2.4 & 78.3 \\
\hline
\end{tabular}

\section{$2.2 \quad$ Operating protocol}

\subsubsection{Scoping trials}

Pressure-step tests were initially conducted to assess the impact of TMP on permeability $K$, where $K=$ Flux/TMP in $\mathrm{L} /\left(\mathrm{m}^{2}\right.$.h.bar) (or LMH/bar), with 60-minute long TMP steps of 0.2 , 0.4, 0.6 and 0.8 bar. A nominal approach CFV of $2 \mathrm{~m} / \mathrm{s}$ was used throughout. Operation was closed loop, with both the permeate and the retentate returned to the feed tank during the testing period to maintain feedwater quality. The ambient temperature throughout the campaign was $\sim 26^{\circ} \mathrm{C}$, and the viscosity around 0.9 Pas.

\subsubsection{Concentration trials}

The main tests were performed under open-loop conditions, with the permeate constantly withdrawn from the system and the retentate returned to the feed tank so as to concentrate the feedwater over the course of the run. The membranes were challenged with feedwaters of 
similar quality (Table 3), and tests conducted under the same base operating and maintenance $(\mathrm{O} \& \mathrm{M})$ conditions (Table 4) with the same membrane CIP procedure (Table 5) employed between runs (i.e. daily). Feedwater and permeate samples were extracted from the feed tank before and after the concentration test for analysis. The tests were run until the feedwater volume had decreased by a factor of 4 . Running to this specific end point ensured that the total hydraulic and pollutant load was approximately the same for each test, assuming the pollutant to be largely retained with the retentate.

Table 4: Operating conditions

\begin{tabular}{l|l}
\hline Parameter & Value \\
\hline Backpulse pressure (bar) & 3 \\
Backpulse duration (s) & 0.8 \\
Backpulse frequency (s) & 330 \\
Backflush pressure (bar) & 3 \\
Backflush duration (s) & 5 \\
Backflush frequency (s) & 900 \\
Recovery (\%) & 20 \\
\hline
\end{tabular}

Table 5: Cleaning-in-place procedure

\begin{tabular}{l|l}
\hline $\begin{array}{l}\text { Reagent, } \sim 50 \mathrm{~L} \\
\text { aliquots }\end{array}$ & $\begin{array}{l}\text { Recirculation time and } \\
\text { temperature }\end{array}$ \\
\hline 1. Mains water & $30 \mathrm{~min}$ at $\sim 25^{\circ} \mathrm{C}$ \\
2. $2 \% \mathrm{NaOH}$ & $30 \mathrm{~min}$ at $\mathrm{pH} 13$ and $45-55^{\circ} \mathrm{C}$ \\
3. Mains water & $30 \mathrm{~min}$ at $\sim 25^{\circ} \mathrm{C}$ \\
4. $2 \%$ citric acid & $30 \mathrm{~min}$ at $\mathrm{pH} 2$ and $45-55^{\circ} \mathrm{C}$ \\
5. Mains water & $30 \mathrm{~min}$ at $\sim 25^{\circ} \mathrm{C}$ \\
\hline
\end{tabular}

TMP and flux data were captured every 3 seconds on the data logger, generating classical saw-tooth transients of flow vs. time (Fig. 2). Data used for comparison of fouling propensity comprised the permeability recorded at the end of the first and final backflush cycle $\left(K_{\text {start }}\right.$ and $K_{\text {final }}$ respectively), along with the total run time $t_{\text {final }}$. The overall permeability decline rate was thus given by $\Delta K / \Delta t=\left(K_{\text {start }}-K_{\text {final }}\right) /\left(t_{\text {final }}-t_{\text {start }}\right), t_{\text {start }}$ being the time at the end of the first backflush cycle. $K_{\text {final }}$ and $\Delta K / \Delta t$ thus provided simple indicators of the sustainability of the filtration process.

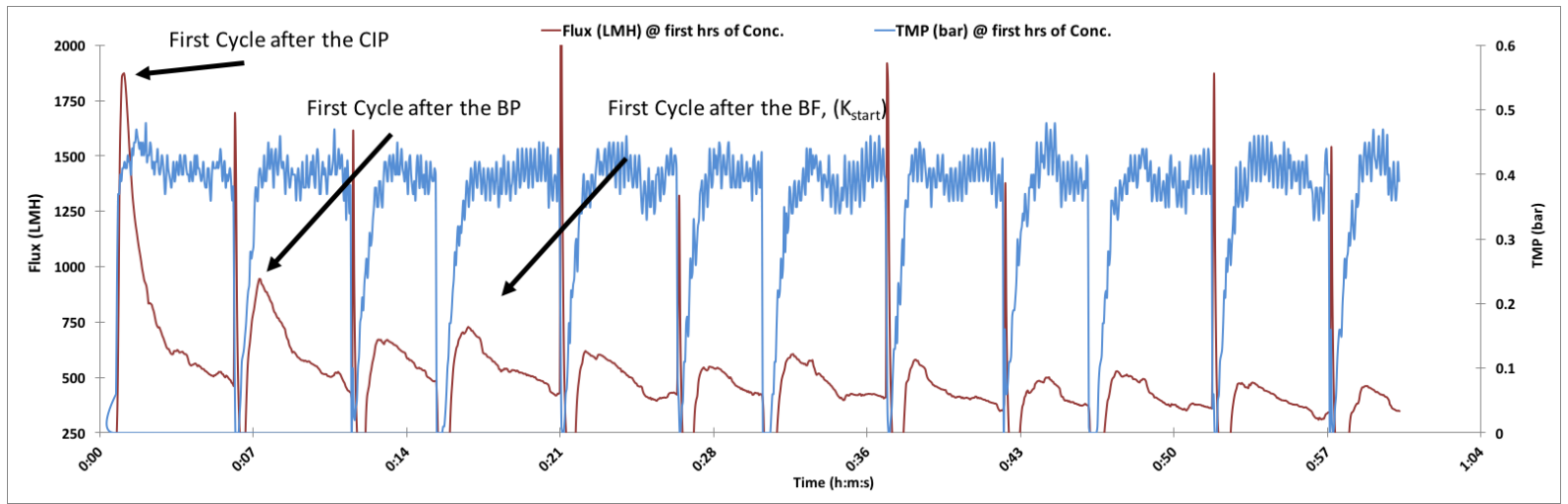

(a)

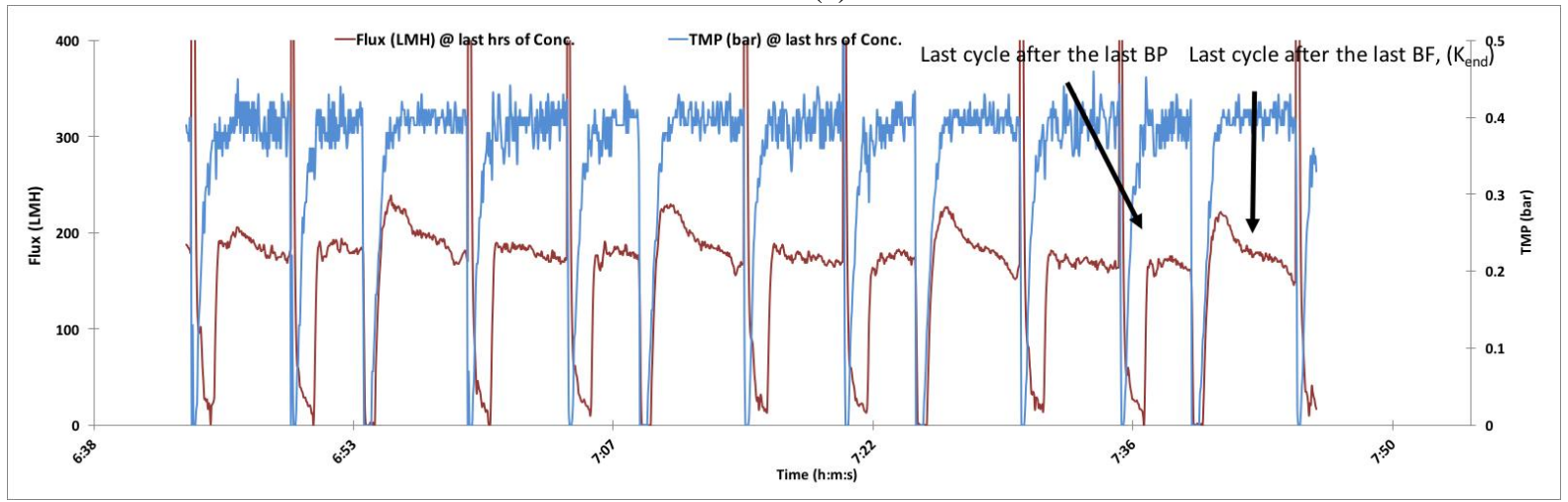

(b)

Figure 2: Typical filtration transient: flux and pressure transient from (a) the beginning and (b) the end of the concentration test, SiC 37-channel UF membrane 


\section{Results and discussion}

\subsection{TMP step trials}

Initial trials conducted in duplicate, in which the pressure was increased in 0.2 bar increments between 0.2 and 0.8 bar, each step lasting 60 minutes, at a recovery of $20 \%$. Operation was closed loop, with both the permeate and the retentate returned to the feed tank during the testing period to maintain feedwater quality. Physical cleaning was as indicated in Table 4 .

Results indicated the flux to increase little above a TMP of 0.4 bar (Fig. 3), though the permeability declined steadily between 0.2 and 0.6 bar. A target TMP of 0.4 bar was selected for all subsequent trials based on these data.

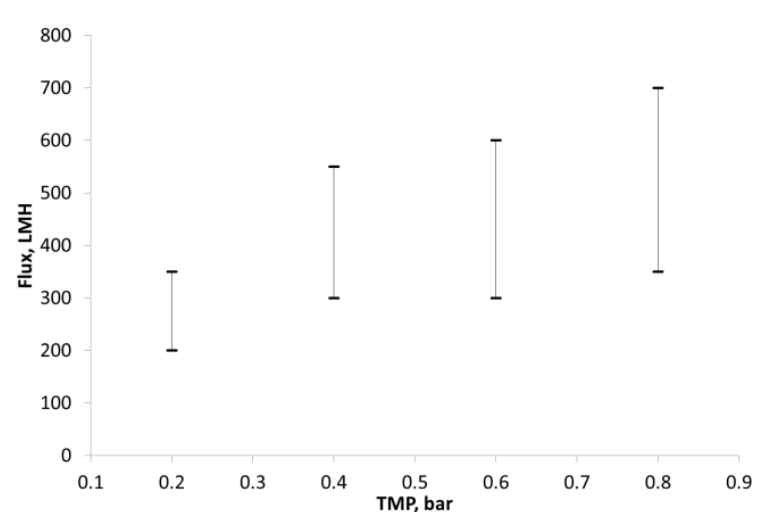

(a)

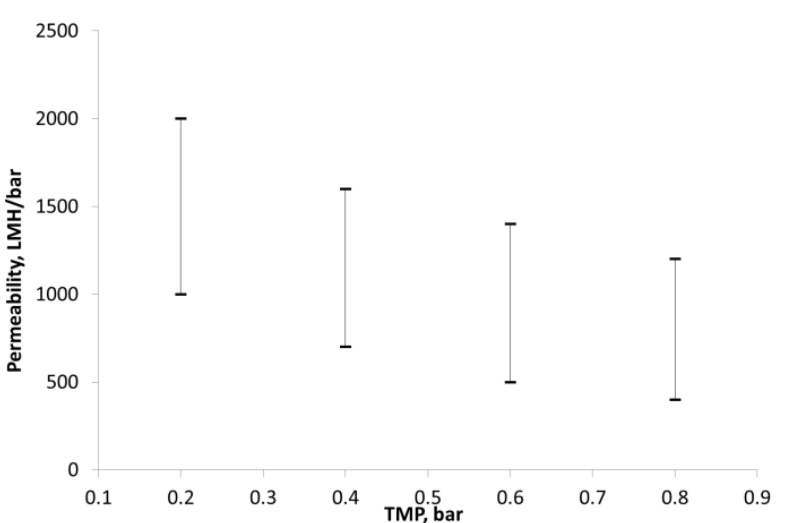

(b)

Figure 3: $\quad$ TMP step scoping trials for $\mathrm{SiC}$ MF membrane, (a) flux, and (b) permeability response

\subsection{Water quality}

Of the water quality parameters studied, significant rejection ( $>70 \%)$ was evident only for oil and grease $(\mathrm{O} \& \mathrm{G})$, turbidity, iron and sulphide, all being associated with suspended material. Feedwater quality measurements revealed that retentate recirculation increased the feed concentration by an average of only $52-162 \%$ for O\&G (Fig. 4a) and $17-146 \%$ for turbidity (Fig. 4b) over the course of the run, despite the volume reduction factor being 4 in all cases. Mean feed O\&G concentrations over the course of the test ranged from 38 to $57 \mathrm{mg} / \mathrm{L}$, with membranes providing $73-86 \%$ removal on average (Fig. 4c). The residual permeate concentration of 6.3 to $7.6 \mathrm{mg} / \mathrm{L}$, across the four membranes tested, was presumed to be associated with dissolved oil. Feed turbidity values ranged from 46 to 102 NTU between batches, with an average of $83-95 \%$ removal rate yielding a mean permeate turbidity of 3.98.0 NTU across all four membranes (Fig. 4d).

The permeate quality appeared to some extent to relate to feedwater quality in the case of the SiC MF membrane permeate turbidity (Fig. 5), for which there was also a marked trend in deteriorating water quality and permeability for consecutive runs (Section 3.3.2). However, the overall performance of all four membranes, in terms of residual pollutant concentration, did not otherwise vary significantly with either membrane material or pore size. 


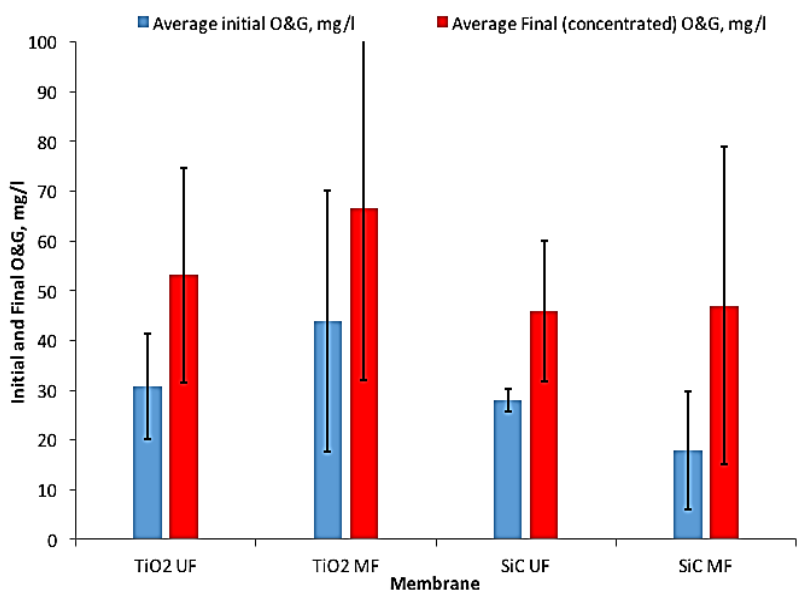

(a)

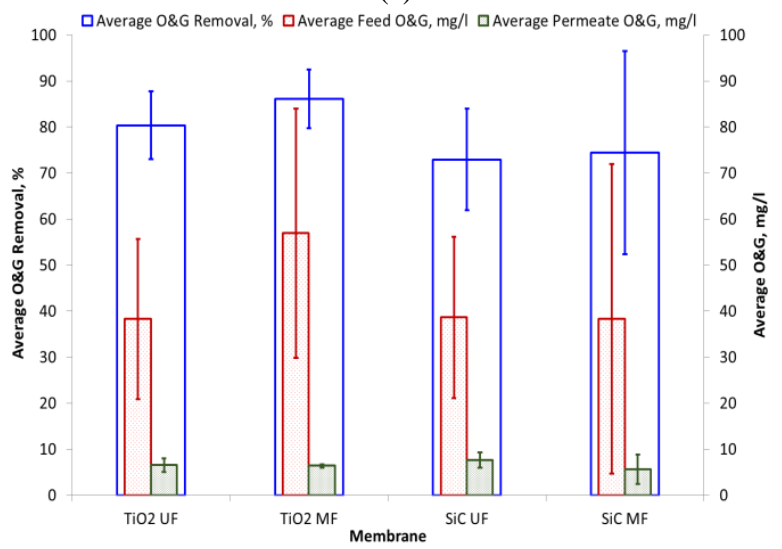

(c)

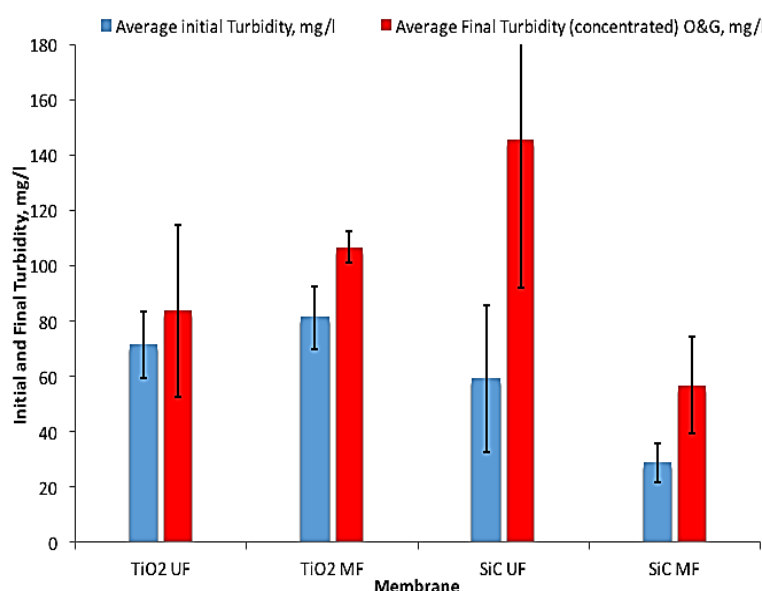

(b)

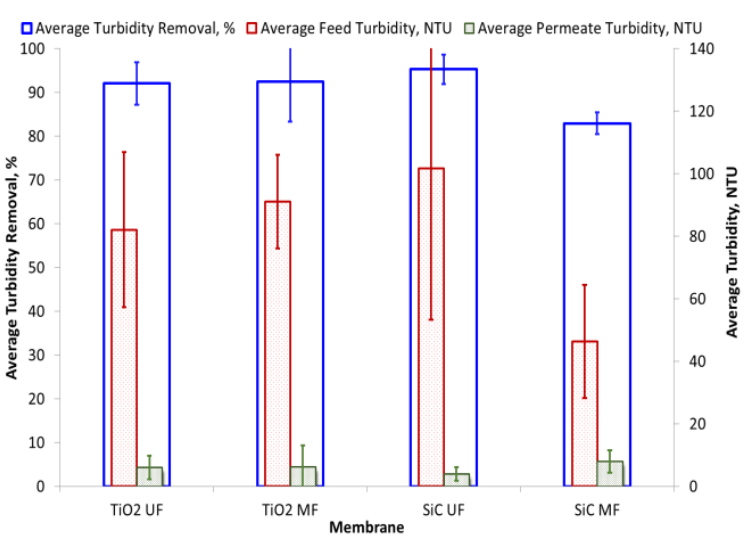

(d)

Figure 4: Initial and final concentrations of feedwater (a) $O \& G$ and (b) turbidity at the start and end of the tests; (c) O\&G and (d) turbidity feed and permeate water concentration and membrane rejection, for the four membrane materials. The error bars indicate the standard deviation (SD) around the mean based on values from 3-4 tests for each membrane.

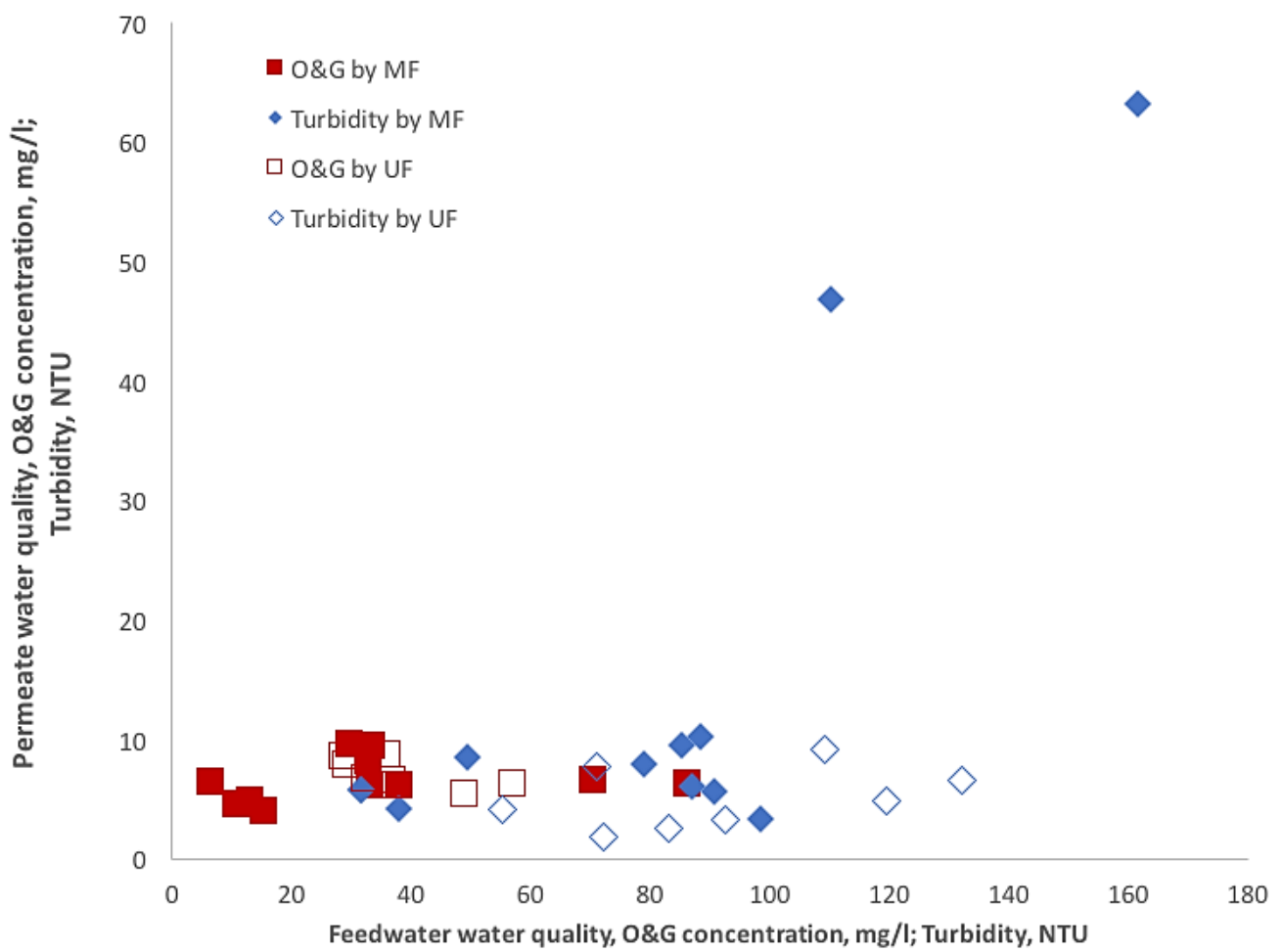

Figure 5: Permeate vs feed concentration for all membranes categorised by selectivity 


\subsection{Fouling rate vs. permeability}

\subsubsection{Data reproducibility}

Trends for mean $K_{\text {final }}$ and $\Delta K / \Delta t$ indicate greater reproducibility for the former than the latter (Fig. 6). These data indicate that the pseudo steady-state response $\left(K_{\text {final }}\right)$ to the total foulant load is more reproducible than the rate at which the membrane fouls $(\Delta K / \Delta t)$. This is a consequence of the time dependency of the feed water quality, which increases in pollutant concentration over the course of the run (Fig. 4a-b). There was no discernable impact of the channel characteristics (number and dimensions) on the recorded trends.

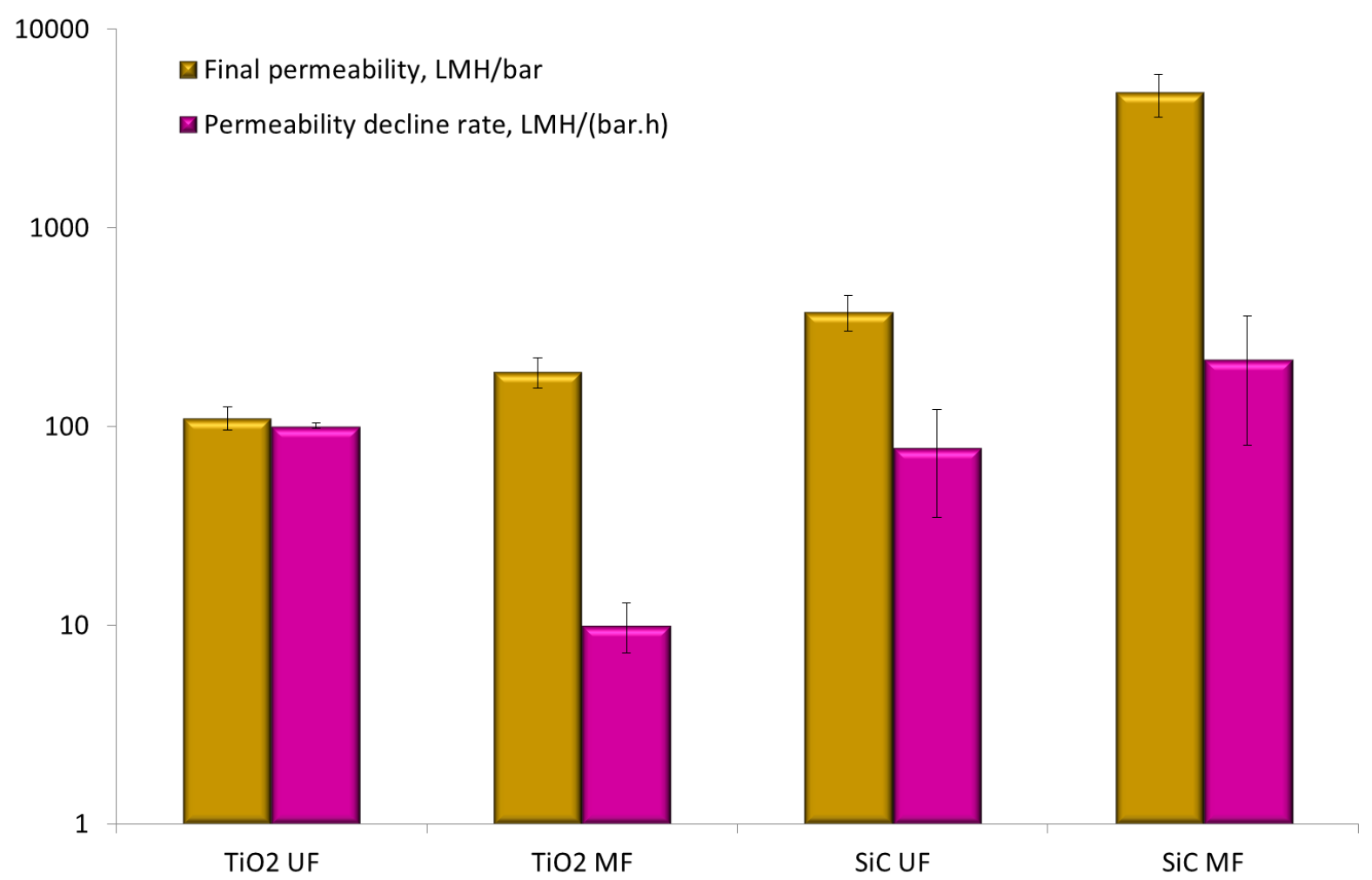

Figure 6: Mean final permeability $\left(K_{f i n}\right)$ and permeability decline rate $(\Delta K / \Delta t)$ across all membranes tested for experimental conditions indicated in Table 4. Error bars indicate SD around the mean permeability value for the 3-4 tests for each membrane.

\subsubsection{Trials}

As expected intuitively, and also from reported flux step studies (Zsirai et al., 2013, Chu et al, $2014), \Delta K / \Delta t$ increases with increasing flux or permeability, roughly in accordance with a power law (Fig 7). Previous comparable studies in PW filtration have been limited to flux vs. TMP correlations (Hua et al, 2007; Vatai et al, 2009; Madaeni et al, 2012), which suggest a similar trend but for which data representing fouling rate (i.e. change in pressure, flux or permeability with time at constant flux or pressure respectively) was not reported. The current data suggest that $\Delta K / \Delta t$ follows an approximate cubic relationship with $K_{\text {final }}$ across three of the four membrane materials studied (Fig. 7), with the SiC MF membrane demonstrating an anomalously high permeability but also a very high fouling rate.

The results demonstrate the efficacy of the $\mathrm{SiC}$ membrane with regards to increased production rate, and therefore reduced footprint (Judd et al, 2014), but also a greater fouling propensity due to the more open pores. The high fouling propensity suggests that either the 
physical cleaning cycle (backpulsing and backflushing) and/or the CIP is/are less effective for the SiC MF membrane than for the other membranes. An examination of the trend in $K_{f}$ values for consecutive runs (Fig. 8) indicates a declining permeability. This is associated with a corresponding declining permeate water quality, and suggests conditioning and internal fouling of the membrane is taking place. This indicates that (a) the high permeability of the $\mathrm{SiC} \mathrm{MF}$ membrane is attained at the expense of rejection, and that (b) a more rigorous CIP protocol is required to maintain performance.

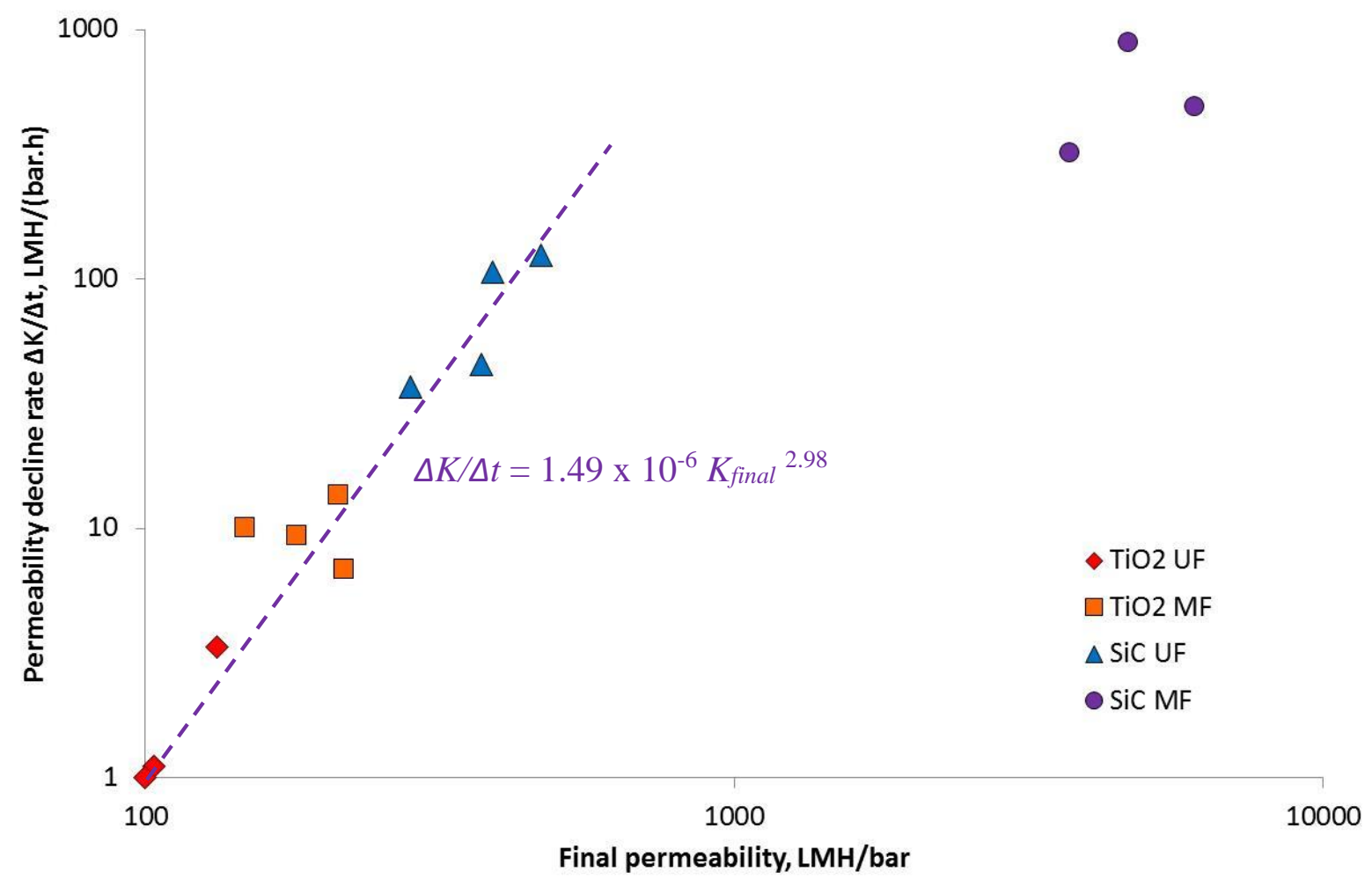

Figure 7: Permeability decline rate $(\Delta K / \Delta t)$ vs. final permeability $\left(K_{f i n}\right)$ for experimental conditions indicated in Table 4

A comparison of values with those reported in the literature indicate generally higher values for the permeability, where $K_{f}=111 \pm 15 \mathrm{LMH} /$ bar to $4780 \pm 1170$ for the current study, cf. values predominantly below $200 \mathrm{LMH} /$ bar for ceramic membrane studies summarised in Table 1. However, even given the increase in pollutant load over the course of the run resulting from retentate recycling, the $O \& G$ concentration levels encountered in the current study (maximum of $\sim 35 \mathrm{mg} / \mathrm{L}$, Fig. 5) were much lower than those reported for real effluents, such as from refineries (Zhong et al, 2003; Madaeni et al, 2013; Weschenfelder et al, 2015b), and from experiments performed using analogues (Vitai et al, 2009; Abassi et al, 2012). The current study also employed a relatively low TMP of 0.4 bar, compared with values generally above 0.5 bar for published studies (Table 1). Against this, some of these ceramic studies have employed pretreatment, such as coagulation (Zhong et al, 2003), coalescers (Motta et al., 2014), multi-stage filtration processes (Ebrahimi et al, 2012), or mechanical shear with rotating ceramic filter discs (Ebrahimi et al, 2013). Some have been based on analogues (Silalahi and Leiknes, 2011; Ebrahimi et al, 2012, 2013; Abassi et al, 2012, Motta et al., 2014), which are known to be less challenging than real waters. A comparison with a recent similar study based on PW of roughly the same quality (Weschenfelder et al, 2015b) indicates permeabilities to be of a comparable order of magnitude. 
Previous studies of CIP efficacy have demonstrated some variability in its effectiveness with regards to permeability recovery. The cleaning efficiency for a $0.2 \mu \mathrm{m}$ alumina membrane using a $1 \%$ caustic solution of proprietary Ultrasil P3-10 cleanant has been reported as being as low as 33\% (Ebrahimi et al, 2010). On the other hand, a study of sequential chemical cleaning with heated water, alkaline hypochlorite, alkaline alkylbenzene sulphonate and finally a citric and glycolic acid solution revealed successive permeability recovery for a 0.1 $\mu \mathrm{m}$ zirconia membrane to around $90 \%$ of the initial permeability (Weschenfelder et al, 2015b). However, there appear to have been no reported studies of refouling, such as that illustrated in Fig. 8. It is apparent that the overall efficacy of the ceramic MF for PW polishing is likely to depend on optimising the chemical cleaning protocol so as to sustain the long-term net permeability, whilst maintaining an overall recovery of $95 \%$ to provide the required economic viability (Weschenfelder et al, 2015c).

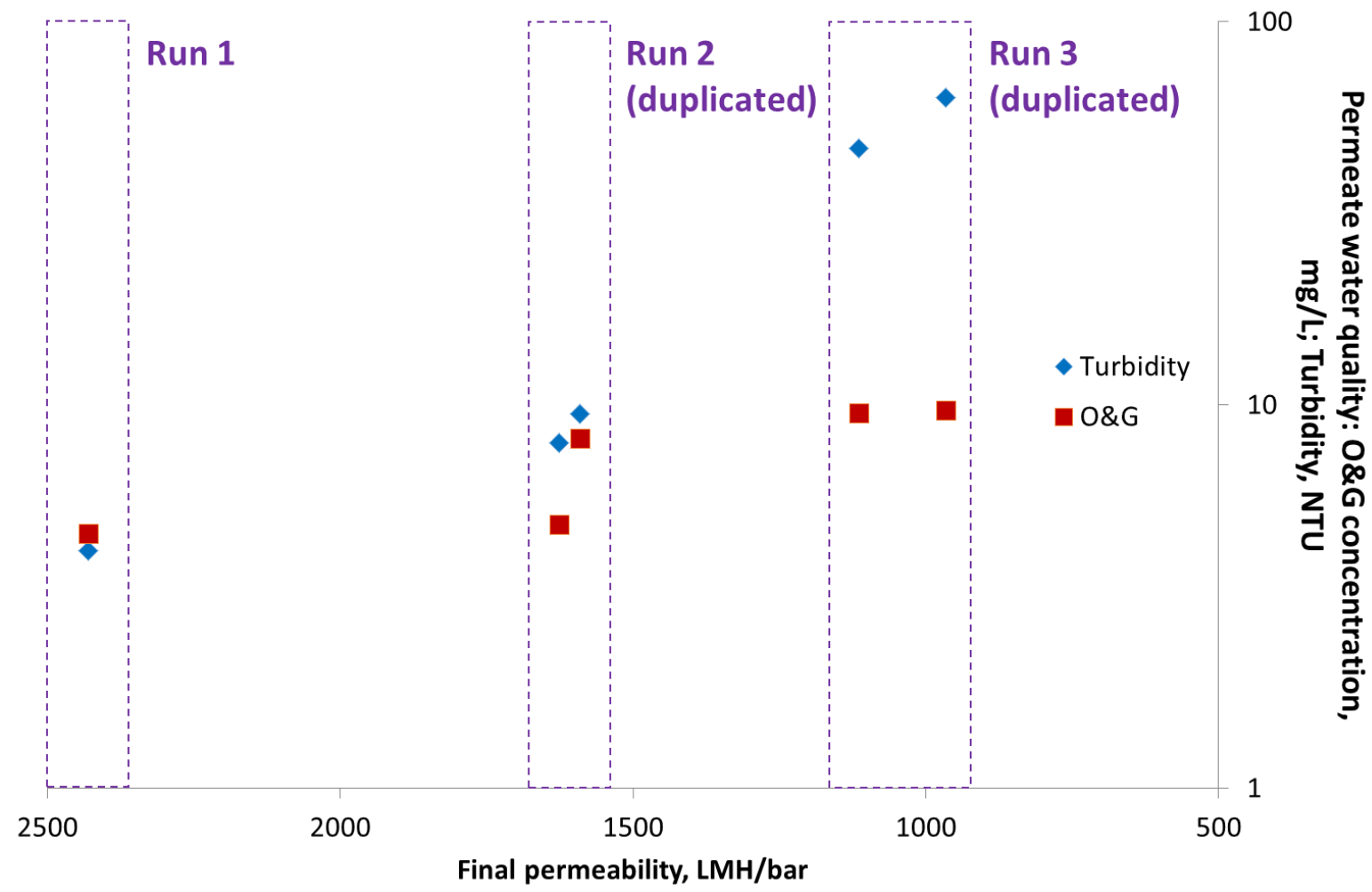

Figure 8: Data permeate water quality vs. final permeability $\left(K_{\text {fin }}\right)$ for consecutive runs, $\mathrm{SiC} \mathrm{MF}$ membrane, for experimental conditions indicated in Table 4

\section{$4 \quad$ Conclusions}

A pilot-scale study of a range of multi-channel ceramic membranes used for produced water (PW) polishing has been conducted using a real PW source taken from the Arabian Gulf. Performance was defined by the overall decline in permeability over the course of the test run $(\Delta K)$ divided by the length of the run $(\Delta t)$, and the permeability at the end of the run $K_{f i n}$.

Results suggest the silicon carbide ( $\mathrm{SiC}$ ) membranes to offer a higher overall permeability than the titanium dioxide $\left(\mathrm{TiO}_{2}\right)$ materials based on the same operating and maintenance conditions of transmembrane pressure, crossflow velocity and physical and chemical cleaning protocol. Three of the four membranes tested demonstrated a cubic relationship between $\Delta K / \Delta t$ and $K_{f i n}$, with the $\mathrm{SiC}$ microfiltration $(\mathrm{MF})$ membrane providing anomalously high 
permeabilities but also the highest fouling propensity. The latter was manifested in both a declining permeability and increased turbidity and O\&M passage between consecutive runs, indicating internal fouling and possible denaturisation of the SiC MF membrane.

The outcomes indicate that whilst the high fluxes (1300-1800 $\mathrm{L} \mathrm{m}^{-2} \mathrm{~h}^{-1}$ ) potentially sustainable infer that low footprints are attainable for the technology, this is contingent upon the application of an effective chemical clean to maintain permeability and treated water quality over a sustained operational period.

\section{Acknowledgements}

The work was been funded by Maersk Oil Qatar, whose help and support is gratefully acknowledged, and was completed as part of project number QUEX-CENG-CHE-13\14-03, Qatar University.

\section{References}

Abbasi, M., Sebzari, M. R., Salahi, A., Abbasi, S., and Mohammadi, T. (2011). Flux decline and membrane fouling in cross-flow microfiltration of oil-in-water emulsions. Desalin. Water Treat., 28(1-3), 1-7.

Alzahrani S., and Mohammad A.W. (2014). Challenges and trends in membrane technology implementation for produced water treatment: A review. J. Water Process Eng., 4 (C), 107133.

APHA (2001). American Public Health Association, Standard methods for the examination of water and wastewater, $22^{\text {nd }} \mathrm{Ed}$, Washington, DC, USA.

Bader, M. (2007) Seawater versus produced water in oil-fields water injection operations, Desalination 208 159-168.

Chakrabarty, B., Ghoshal, A.K., and Purkait, M.K. (2010). Cross-flow ultrafiltration of stable oil-in-water emulsion using polysulfone membranes. Chem. Eng. J., 165 (2), 447-456.

Chu, K.H., Yoo, S.S., Ahn, J.Y., Jo, J.S., and Ko, K.B. (2014). Determining flux behavior via a modified flux-step method for surface water treatment: Pilot-scale ultrafiltration membrane operation. Desalination, 341 (1), 19-26.

Ebrahimi, M., Willershausen, D., Ashaghi, K.S., Engel, L., Placido, L., Mund, P., Bolduan, P., and Czermak (2010). Investigations on the use of different ceramic membranes for efficient oil-field produced water treatment. Desalination, 250, 991-6.

Ebrahimi M., Kovacs Z., Schneider M., Mund P., Bolduan P., and Czermak P. (2012). Multistage filtration process for efficient treatment of oil-field produced water using ceramic membranes. Desalin. Water Treat., 42 (1-3), 17-23.

Ebrahimi, M., Schmitz, O., Kerker, S., Liebermann, F., and Czermak, P. (2013). Dynamic cross-flow filtration of oilfield produced water by rotating ceramic filter discs. Desalin. Water Treat., 49 (1-3), 272-280.

Guirgis, A., Gay-de-Montella, R., and Faiz, R. (2015). Treatment of produced water streams in SAGD processes using tubular ceramic membranes. Desalination, 358, 27-32. 
Hua F.L., Tsang Y.F., Wang Y.J., Chan S.Y., Chua H., and Sin S.N. (2007). Performance study of ceramic microfiltration membrane for oily wastewater treatment. Chem. Eng. J., 128 (2-3), 169-175.

Judd S., Qiblawey H., Al-Marri M., Clarkin C., Watson S., Ahmed A., and Bach S. (2014). The size and performance of offshore produced water oil-removal technologies for reinjection. Sep. Purif. Technol., 134, 241-246.

Lee, J.M., and Frankiewicz, T. (2005). Treatment of produced water with an ultrafiltration (UF) membrane - A field trial. SPE Annual Technical Conference Proceedings

Li L., and Lee R. (2009). Purification of produced water by ceramic membranes: Material screening, process design and economics. Sep. Sci. Technol., 44 (15), 3455-3484.

Madaeni, S, Gheshlaghi, A. and Rekabdar F. (2013). Membrane treatment of oily wastewater from refinery processes, Asia-Pac. J. Chem. Eng., 8(1), 45-53.

Motta A., Borges C., Esquerre K., and Kiperstok A. (2014). Oil Produced Water treatment for oil removal by an integration of coalescer bed and microfiltration membrane processes. $\mathrm{J}$. Membrane Sci., 46, 371-378.

Mueller, J., Cen, Y.W., and Davis, R.H. (1997). Crossflow microfiltration of oily water. J. Membrane Sci. 129 221-235.

Padaki M., Surya Murali R., Abdullah M.S., Misdan N., Moslehyani A., Kassim M.A., Hilal N., and Ismail A.F., (2015). Membrane technology enhancement in oil-water separation. A review. Desalination, 357, 197-207.

Pedenaud, P., Heng, S., Evans, W., and Bieonneau, D. (2011). Ceramic membrane and core pilot results for produced water, OTC-22371-PP, paper presented at Offshore Technology Conference, 4-6 Oct, Rio de Janeiro.

Prado-Rubio, O.A., Cardona, D., Svendsen, T., and Yuan L. (2012). SiC membrane pilot plant ultrafiltration test for produced water treatment, Ocelote field - Hocol (COLOMBIA). Company report, Liqtech.

Reyhani, A., and Mashhadi Meighani, H. (2015). Optimal operating conditions of micro- and ultra-filtration systems for produced-water purification: Taguchi method and economic investigation. Desalin. Water Treat. (Article in Press).

Robinson, D. (2010) . Oil and gas: Water treatment in oil and gas production - does it matter? Filtration and Separation, 47 (1), pp. 14-18.

Robinson, D. (2013). Oil and gas: Treatment of produced waters for injection and reinjection. Filtration and Separation, 50 (4), 36-43.

Silalahi, S.H.D., and Leiknes, T., (2009). Cleaning strategies in ceramic microfiltration membranes fouled by oil and particulate matter in produced water. Desalination, 236 (1-3), 160-169.

Subramani, A., Schlicher, R., Long, J., Yu, J., Lehman, S., and Jacangelo, J. G. (2011). Recovery optimization of membrane processes for treatment of produced water with high silica content. Desalin. Water Treat., 36(1-3), 297-309.

Vatai, G. N., Krstić, D. M., Koris, A. K., Gáspár, I. L., and Tekić, M. N. (2009). Ultrafiltration of oil-in-water emulsion: Comparison of ceramic and polymeric membranes. Desalin. Water Treat., 3(1-3), 162-168. 
Weschenfelder, S.E., Borges, C.P., and Campos, J.C. (2015a). Oilfield produced water treatment by ceramic membranes: Bench and pilot scale evaluation. J. Membrane Sci., 495, 242-251.

Weschenfelder S.E., Louvisse A.M.T., Borges C.P., Meabe E., Izquierdo J., and Campos J.C. (2015b). Evaluation of ceramic membranes for oilfield produced water treatment aiming reinjection in offshore units. J. of Petrol. Sci. Eng., 131, 51-57.

Weschenfelder S.E., Mello A.C.C., Borges C.P., and Campos J.C. (2015c). Oilfield produced water treatment by ceramic membranes: Preliminary process cost estimation. Desalination, 360, 81-86.

Yang, C., Zhang, G., Xu, N., and Shi, J. (1998). Preparation and application in oil-water separation of ZrO2/ $\alpha$-A12O3 MF membrane. J. Membrane Sci., 142 (2), 235-243

Zaidi, A., Simms, K., Kok, S., and Nelson, R. (1992). Recent advances in the application of membrane technology for the removal of oil and suspended solids from produced waters, in "Produced Water" (Eds. J. P. Ray and F. R. Engelhardt), Environmental Science Research series, 46 489-501.

Zhong, J., Sun, X., and Wang, C. (2003). Treatment of oily wastewater produced from refinery processes using flocculation and ceramic membrane filtration. Sep. Purif. Technol., 32, 1-3, 93-98.

Zsirai, T., Aerts, P., and Judd, S. (2013). Reproducibility and applicability of the flux step test for a hollow fibre membrane bioreactor. Sep. Purif. Technol., 107, 144-149. 